\title{
Gut microbes and host physiology: what happens when you host billions of guests?
}

\author{
Jennifer L. Pluznick* \\ Department of Physiology, Johns Hopkins University School of Medicine, Baltimore, MD, USA \\ *Correspondence: Jpluznick@jhmi.edu \\ Edited by: \\ Ikuo Kimura, Tokyo University of Agriculture and Technology, Japan \\ Reviewed by: \\ Undurti Narasimha Das, UND Life Sciences, USA
}

Keywords: gut microbiota, gut bacteria, host physiology, short-chain fatty acids, gut metabolites

The gut microbiota has recently emerged as an important, and previously unappreciated, player in host physiology (1). In particular, the gut microbiota contributes to a variety of physiological and pathophysiological processes in the host including immune disorders (2-4), atherosclerosis (5), irritable bowel syndrome $(6,7)$, blood pressure regulation (8), and chronic kidney disease $(9,10)$. Bacteria residing in the human gut are an important component of human physiology: the total wet weight of gut microbes in the human has been estimated to be $175 \mathrm{~g}-1.5 \mathrm{~kg}(11,12)$, and the cells of the microbiota outnumber human cells by 10:1 (1). These bacteria interact with the immune system of the host (13), and secrete a variety of metabolites, which enter host circulation and can affect a variety of physiological parameters $(8,14)$, reviewed in Ref. (15). In fact, metabolites produced by the gut microbiota have been found to play key roles in renal disease (16), blood pressure regulation (8), and immune disorders (2-4). Therefore, just as we consider the genetic background of an animal or an individual to be an important contributing factor to their physiology, so too must we consider the genetic background of the microbiota associated with that animal.

Gut microbiota vary greatly amongst laboratory animals, and these differences result in notable differences in experimental results. Mice of the same strain from different vendors have different microbiota profiles (17), and similarly, the same mice housed at different institutions have different microbiota profiles $(18,19)$. Conversely, inoculating two different inbred mouse strains with the same gut bacteria leads to differences in host gene expression between the two mouse strains
(20). Clearly, there is a complex interplay between the genetics of the microbiota and that of the host organism, which has only recently begun to be appreciated.

\section{GUT MICROBIOTA AS AN EXPERIMENTAL PARAMETER}

Examples in the literature have highlighted the important and unexpected ways in which gut microbiota can affect a variety of experimental parameters. In a series of studies, Vijay-Kumar et al. $(13,21)$ reported that although TLR5 null animals initially had a colitis phenotype, when these mice were "rederived" and their gut microbiota altered, the colitis phenotype was greatly attenuated, and instead the null animals exhibited metabolic syndrome. In addition, Lathrop et al. put forward a model by which T-cells are educated not only by self/nonself mechanisms, but also by microbiotaderived "non-self" antigens (22). Accordingly, they found that the presence or absence of microbiota determined whether T cells would induce colitis in mice. Finally, Yang et al. reported that when the same knockout mice were housed at two different institutions, they had markedly different microbiota profiles - and the mice at one institution (MIT) were quite susceptible to colitis, whereas mice at the other institution (MHH) failed to develop any significant pathology under the same conditions (19). Unequivocally, altering gut microbiota - even by housing animals at different institutions - can have dramatic effects on the phenotype observed.

\section{GUT MICROBIOTA AND OBESITY AND DIABETES}

It is important to note that not only can microbiota affect host physiology, but the gut microbiota are not necessarily stable over time. Rather, gut microbiota can change or shift as a result of experimental manipulation (in animals) or changes in lifestyle or nutrition (in humans). It is now appreciated that there are "shifts" in microbiota that occur in obesity in mice, rats, and humans (23-26). In one study, Turnbaugh et al. (25) examined human female twin pairs concordant for leanness or obesity, and found that obesity was associated with phylum-level changes in microbiota. In this study, both monozygotic and dizygotic female twin pairs (and their mothers, where available) were analyzed. Analysis of fecal samples revealed that obese individuals have reduced gut microbiota diversity, and tended to have less Bacteroidetes and more Actinobacteria. The authors suggest that conditions of "abnormal energy input" (i.e., obesity) may favor the growth of a reduced diversity community. In support of these findings, a separate study reported that ob/ob mice had a reduction in Bacteroidetes (27) as compared to ob/+ or wild-type siblings. Furthermore, in 12 obese humans who lost weight over 1 year by consuming either a fat restricted or caloric restricted diet, there was a relative increase in the abundance of Bacteroidetes over time (28). Impressively, the increase in Bacteroidetes in these individuals correlated with weight loss. Indeed, there is an increasingly convincing link between gut microbiota and obesity. These findings highlight the importance of considering and documenting gut microbiota composition in studies of obesity, as a change in gut microbiota structure has a clear tie to host pathology.

In addition, it has also been demonstrated that type 2 diabetes in humans is associated with changes in the gut microbiota (not surprising, given the 
correlation between obesity and type 2 diabetes) (29-33). Specifically, it has been reported that butyrate-producing bacteria are reduced in type 2 diabetes (32), that Bifidobacterium is lowered (33), and that Firmicutes is decreased (30). Intriguingly, it was also reported that the ratio of Bacteroidetes to Firmicutes (as well as the ratio of Bacteroides-Prevotella to C. CoccoidesE. rectale) correlated with plasma glucose levels. Subsequently, it has been suggested that manipulating gut microbiota may be a therapeutic opinion for obesity and/or type 2 diabetes (34). As reviewed in depth by Kootte et al. (34), in addition to exploring possible roles for prebiotics, probiotics, and antibiotics as potential therapies, we must also better understand the changes in microbiota which appear to accompany known treatments for obesity (i.e., bariatric surgery). In addition, we must continue to explore a potential role for a variety of microbiota metabolites in order to better understand how and why changes in microbiota affect the physiology of the host.

\section{WHAT'S A SCIENTIST TO DO?}

Knowing that gut microbiota play such an important and dynamic role in host physiology, going forward we should take into account (or at least, document) the gut microbiota present in whole-animal physiology experiments. This is especially important in research focused on obesity and diabetes, as these are areas in which gut microbiota changes have been associated with host pathology. As the study of the gut microbiota requires a specialized and complex set of knowledge, it may be prudent for Universities, Companies, or other Research Entities to establish core facilities and/or collaborations to help facilitate such measurements. In addition, when differences are found in measured physiological parameters between researchers at different institutions, gut microbiota should be considered as one potential explanation. Finally, as different strains of microbiota produce different metabolites, metabolomics may also be a useful tool to help us understand the "end effect" of microbiota on host function.

\section{CONCLUSION}

The gut microbiota is a complex tangle of organisms, which easily outnumber the number of cells in the host. When considering processes in the context of wholeanimal physiology, we must also consider the contribution of these microorganisms and their metabolites. The literature is rife with examples of phenotypes which were not easily replicated by other groups even when using the "same mice" - and we should consider whether some of these examples may be, in fact, due to the influence of gut microbiota. In the future, it would be ideal for researchers to report at least a basic characterization of gut microbiota in research animals so that any "institution-specific" effects can later be examined. Understanding not only the host and the microbiota, but the hostmicrobiota interactions, will ultimately give us a richer and fuller understanding of host physiology.

\section{ACKNOWLEDGMENTS}

The author would like to thank Dr. Daniel Peterson (Johns Hopkins) as well as the members of the Pluznick Lab for helpful discussions of the literature, and Dr. Vinita Takiar (MD Anderson) for helpful comments.

\section{REFERENCES}

1. Sekirov I, Russell SL, Antunes LC, Finlay BB. Gut microbiota in health and disease. Physiol Rev (2010) 90:859-904. doi:10.1152/physrev. 00045.2009

2. Berer K, Mues M, Koutrolos M, Rasbi ZA, Boziki $\mathrm{M}$, Johner C, et al. Commensal microbiota and myelin autoantigen cooperate to trigger autoimmune demyelination. Nature (2011) 479:538-41. doi:10.1038/nature 10554

3. Hwang JS, Im CR, Im SH. Immune disorders and its correlation with gut microbiome. Immune Netw (2012) 12:129-38. doi:10.4110/in.2012.12.4.129

4. Maslowski KM, Vieira AT, Ng A, Kranich J, Sierro F, Yu D, et al. Regulation of inflammatory responses by gut microbiota and chemoattractant receptor GPR43. Nature (2009) 461:1282-6. doi:10.1038/ nature 08530

5. Wang Z, Klipfell E, Bennett BJ, Koeth R, Levison BS, Dugar B, et al. Gut flora metabolism of phosphatidylcholine promotes cardiovascular disease. Nature (2011) 472:57-63. doi:10.1038/ nature09922

6. Dahlqvist G, Piessevaux H. Irritable bowel syndrome: the role of the intestinal microbiota, pathogenesis and therapeutic targets. Acta Gastroenterol Belg (2011) 74:375-80.

7. DuPont AW, DuPont HL. The intestinal microbiota and chronic disorders of the gut. Nat Rev Gastroenterol Hepatol (2011) 8:523-31. doi:10.1038/ nrgastro.2011.133

8. Pluznick JL, Protzko RJ, Gevorgyan H, Peterlin Z, Sipos A, Han J, et al. Olfactory receptor responding to gut microbiota-derived signals plays a role in renin secretion and blood pressure regulation. Proc Natl Acad Sci U S A (2013) 110:4410-5. doi:10.1073/pnas.1215927110

9. Vaziri ND. CKD impairs barrier function and alters microbial flora of the intestine: a major link to inflammation and uremic toxicity. Curr Opin Nephrol Hypertens (2012) 21:587-92. doi:10.1097/ MNH.0b013e328358c8d5

10. Vaziri ND, Yuan J, Norris K. Role of urea in intestinal barrier dysfunction and disruption of epithelial tight junction in chronic kidney disease. Am J Nephrol (2013) 37:1-6. doi:10.1159/000345969

11. Bugaut M. Occurrence, absorption and metabolism of short chain fatty acids in the digestive tract of mammals. Comp Biochem Physiol B (1987) 86:439-72.

12. Hill MJ, Drasar BS. The normal colonic bacterial flora. Gut (1975) 16:318-23. doi:10.1136/gut.16.4. 318

13. Vijay-Kumar M, Sanders CJ, Taylor RT, Kumar A, Aitken JD, Sitaraman SV, et al. Deletion of TLR5 results in spontaneous colitis in mice. J Clin Invest (2007) 117:3909-21. doi:10.1172/JCI33084

14. Samuel BS, Shaito A, Motoike T, Rey FE, Backhed F, Manchester JK, et al. Effects of the gut microbiota on host adiposity are modulated by the short-chain fatty-acid binding $\mathrm{G}$ protein-coupled receptor, Gpr41. Proc Natl Acad Sci U S A (2008) 105:16767-72. doi:10.1073/pnas.0808567105

15. Nicholson JK, Holmes E, Kinross J, Burcelin R, Gibson G, Jia W, et al. Host-gut microbiota metabolic interactions. Science (2012) 336:1262-7. doi: $10.1126 /$ science. 1223813

16. Jang HR, Gandolfo MT, Ko GJ, Satpute S, Racusen L, Rabb H. Early exposure to germs modifies kidney damage and inflammation after experimental ischemia-reperfusion injury. Am J Physiol Renal Physiol (2009) 297:F1457-65. doi:10.1152/ ajprenal.90769.2008

17. Hufeldt MR, Nielsen DS, Vogensen FK, Midtvedt $\mathrm{T}$, Hansen AK. Variation in the gut microbiota of laboratory mice is related to both genetic and environmental factors. Comp Med (2010) 60:336-47.

18. Friswell MK, Gika H, Stratford IJ, Theodoridis G, Telfer B, Wilson ID, et al. Site and strain-specific variation in gut microbiota profiles and metabolism in experimental mice. PLoS One (2010) 5:e8584. doi:10.1371/journal.pone.0008584

19. Yang I, Eibach D, Kops F, Brenneke B, Woltemate $\mathrm{S}$, Schulze J, et al. Intestinal microbiota composition of interleukin-10 deficient C57BL/6J mice and susceptibility to Helicobacter hepaticus-induced colitis. PLoS One (2013) 8:e70783. doi:10.1371/ journal.pone.0070783

20. Brodziak F, Meharg C, Blaut M, Loh G. Differences in mucosal gene expression in the colon of two inbred mouse strains after colonization with commensal gut bacteria. PLoS One (2013) 8:e72317. doi:10.1371/journal.pone.0072317

21. Vijay-Kumar M, Aitken JD, Carvalho FA, Cullender TC, Mwangi S, Srinivasan S, et al. Metabolic syndrome and altered gut microbiota in mice lacking Toll-like receptor 5. Science (2010) 328:228-31. doi:10.1126/science.1179721

22. Lathrop SK, Bloom SM, Rao SM, Nutsch K, Lio CW, Santacruz N, et al. Peripheral education of the immune system by colonic commensal microbiota. Nature (2011) 478:250-4. doi:10. 1038/nature 10434 
23. de La Serre CB, Ellis CL, Lee J, Hartman AL, Rutledge JC, Raybould HE. Propensity to highfat diet-induced obesity in rats is associated with changes in the gut microbiota and gut inflammation. Am J Physiol Gastrointest Liver Physiol (2010) 299:G440-8. doi:10.1152/ajpgi.00098.2010

24. Turnbaugh PJ, Backhed F, Fulton L, Gordon JI. Diet-induced obesity is linked to marked but reversible alterations in the mouse distal gut microbiome. Cell Host Microbe (2008) 3:213-23. doi:10. 1016/j.chom.2008.02.015

25. Turnbaugh PJ, Hamady M, Yatsunenko T, Cantarel BL, Duncan A, Ley RE, et al. A core gut microbiome in obese and lean twins. Nature (2009) 457:480-4. doi:10.1038/nature07540

26. Turnbaugh PJ, Ley RE, Mahowald MA, Magrini V, Mardis ER, Gordon JI. An obesity-associated gut microbiome with increased capacity for energy harvest. Nature (2006) 444:1027-31. doi:10.1038/ nature 05414

27. Ley RE, Backhed F, Turnbaugh P, Lozupone CA, Knight RD, Gordon JI. Obesity alters gut microbial ecology. Proc Natl Acad Sci U S A (2005) 102:11070-5. doi:10.1073/pnas.0504978102

28. Ley RE, Turnbaugh PJ, Klein S, Gordon JI. Microbial ecology: human gut microbes associated with obesity. Nature (2006) 444:1022-3. doi:10.1038/ $4441022 \mathrm{a}$
29. Everard A, Cani PD. Diabetes, obesity and gut microbiota. Best Pract Res Clin Gastroenterol (2013) 27:73-83. doi:10.1016/j.bpg.2013.03. 007

30. Larsen N, Vogensen FK, van den Berg FW, Nielsen DS, Andreasen AS, Pedersen BK, et al. Gut microbiota in human adults with type 2 diabetes differs from non-diabetic adults. PLoS One (2010) 5:e9085. doi:10.1371/journal.pone. 0009085

31. Musso G, Gambino R, Cassader M. Interactions between gut microbiota and host metabolism predisposing to obesity and diabetes. Annu Rev Med (2011) 62:361-80. doi:10.1146/annurevmed-012510-175505

32. Qin J, Li Y, Cai Z, Li S, Zhu J, Zhang F, et al. A metagenome-wide association study of gut microbiota in type 2 diabetes. Nature (2012) 490:55-60. doi:10.1038/nature11450

33. Wu X, Ma C, Han L, Nawaz M, Gao F, Zhang $\mathrm{X}$, et al. Molecular characterisation of the faecal microbiota in patients with type II diabetes. Curr Microbiol (2010) 61:69-78. doi:10.1007/s00284010-9582-9

34. Kootte RS, Vrieze A, Holleman F, Dallinga-Thie GM, Zoetendal EG, de Vos WM, et al. The therapeutic potential of manipulating gut microbiota in obesity and type 2 diabetes mellitus. Diabetes
Obes Metab (2012) 14:112-20. doi:10.1111/j.14631326.2011.01483.x

Conflict of Interest Statement: The author declares that the research was conducted in the absence of any commercial or financial relationships that could be construed as a potential conflict of interest.

Received:08 May 2014; accepted:01 June 2014; published online: 13 June 2014.

Citation: Pluznick JL (2014) Gut microbes and host physiology: what happens when you host billions of guests? Front. Endocrinol. 5:91. doi: 10.3389/fendo.2014.00091

This article was submitted to Diabetes, a section of the journal Frontiers in Endocrinology.

Copyright (c) 2014 Pluznick. This is an open-access article distributed under the terms of the Creative Commons Attribution License (CC BY). The use, distribution or reproduction in other forums is permitted, provided the original author(s) or licensor are credited and that the original publication in this journal is cited, in accordance with accepted academic practice. No use, distribution or reproduction is permitted which does not comply with these terms. 